\title{
Using Fuzzy Sets and Markov Chain Method to Carry out Inventory Strategies with Different Recovery Levels
}

\author{
Tseng-Fung Ho ${ }^{1}\left(\mathbb{O}\right.$, Chi-Chung Lin $^{1}$ and Chih-Ling Lin ${ }^{2, *}$ \\ 1 Department of Industrial Engineering and Management, National Chin-Yi University of Technology, \\ Taichung 41170, Taiwan; fung@ncut.edu.tw (T.-F.H.); chclin.lin0502@msa.hinet.net (C.-C.L.) \\ 2 Department of International Business, Central Taiwan University of Science and Technology, \\ Taichung 40601, Taiwan \\ * Correspondence: cllin101938@ctust.edu.tw; Tel.: +886-4-22391647 (ext. 7266)
}

Received: 7 June 2020; Accepted: 24 July 2020; Published: 26 July 2020

\begin{abstract}
In this study, we first analyze the usability of recycling products, and use the fuzzy set method to determine the main impact on recycling items and their corresponding weights by using the Analytic Hierarchy Process (AHP) to identify various impact recycling levels. The Group Decision Supporting System (GDSS) determines the test standards for the recycling rating. It provides a convenient way for recyclers or manufacturers to classify their own products and use fuzzy numbers to select a set of test standards. It can deduce the recovery rate and remanufacturing rate of different recycling processing levels through the Markov chain model to find out the inventory model and total cost. In the numerical analysis, we found that a recycling rate of more than $90 \%$ is probably a necessary decision. Since the processing cost of the $100 \%$ recovery rate is doubled, the inventory level and total cost will increase with it. Therefore, this study was combined with the reverse logistics method to find the appropriate decision-making strategy and plan, such as the optimal inventory level and recovery rate.
\end{abstract}

Keywords: green supply chain; reverse logistics; inventory; fuzzy; markov chain

\section{Introduction}

In the past decade, due to the increasing demand for green products worldwide, the issue of green productivity has gradually attracted attention. Some of the latest laws passed in Europe are examples of such strong requirements, including the Waste Electrical and Electronic Equipment Directive 2002/96/EC (WEEE) and Restriction of Hazardous Substances (RoHS) standards, which have placed great pressure on product designers and manufacturers to produce greener and cleaner products. However, if individual companies respond to these requests, the problem may not be solved effectively. Instead, the trend is to provide an overall product supply chain operation strategy. Under the competition of the global economy and environment, the product life cycle seems to be shorter than before. The competition and survival of the company must incorporate the reverse supply chain into the management. On the other hand, environmental protection will also affect the corporate image. Therefore, for the sake of ecological protection and sustainable business operation, the integration of suppliers and buyers in successful supply chain management is one of the main successful methods.

Reverse logistics represents a series of logistics activities that recover used products from consumers and reuse this resource in the market. In the past, the reverse logistics was mostly based on the product production and recycling of Thierry M.C (1995) [1]. Fleischmann (1997) [2]; Carter and Ellram (1998) [3]; Guide (2002) [4] and other studies also revealed that the distribution cost of recycling reverse logistics is often higher than that of forward logistics. For the returned products, there are also irregular channels 
in terms of transportation, storage, processing, and management, which adds a lot of complexity and uncertainty to the supply chain. Therefore, LA Zadeh (1973) [5] obtains the correct result through the approximation reasoning process, which is very similar to the human brain "process is fuzzy, the conclusion is clear" thinking mode, so Jang et al. (1996) [6] is widely used in various intelligent systems in different fields.

Then, Zipkin (1993) [7] used the Markov chain to develop a model of dynamic interest rate evaluation of real estate mortgage-backed securities. Aase (2001) [8] uses the Markov model to provide an assessment theory for the catastrophe's long-term contract or derivative commodity insurance. Ching et al. (2002) [9], Naranjo, L, et al. (2019) [10], Lizbeth Naranjo, et al. (2020) [11] apply the Markov chain to develop a multivariable Markov chain to predict customer demand. The reverse logistics environment still needs to integrate the upstream and downstream supply chains, so Lin and Lin (2011) [12], Lin and Su (2013) [13], Verhoeven and Sinn (2018) [14] and Ho and Lin (2020) [15], for the overall logistics supply chain with the lowest overall cost as the target, consider the defective products level, inventory cost, transportation and other expenses. To aim at the overall logistics supply chain with the lowest overall total cost, we have to consider the cost of bad goods, inventory cost, transportation and so on. Minner and Kiesmüller (2012) [16] explored the closed supply chain in a dynamic model. Xin et al. (2019) [17] and Kannan et al. (2020) [18] used fuzzy theory to solve the closed supply chain model.

In this paper, we extend the single-item single-location inventory system of Erwin et al. (1996) [19] with multiple-items and multiple-periods. We consider the recovery rate and remanufacturing rate of different recycle processing levels and combine reverse logistics methods to develop a set of mathematical inventory models. In the results of numerical analysis, we show the effects of different recycling levels.

\section{Model Description}

The impact of environmental responsibility on the manufacturing business model is becoming higher and higher, and the products produced by different industries have different environmental loads. Moreover, the life of the product will vary with the frequency of use or the environment, resulting in differences in surface luminosity, short circuit, damage, or scrapping process. Products produced in different industries have different environmental hazards and different levels of recycling. This study considers different recycling levels for a single project as shown in Figure 1 (Thierry, M., et al. (1995) [1]). In other words, the recycling status can be roughly divided into transfer, polishing, maintenance, remanufacturing, crushing, burying, incineration.
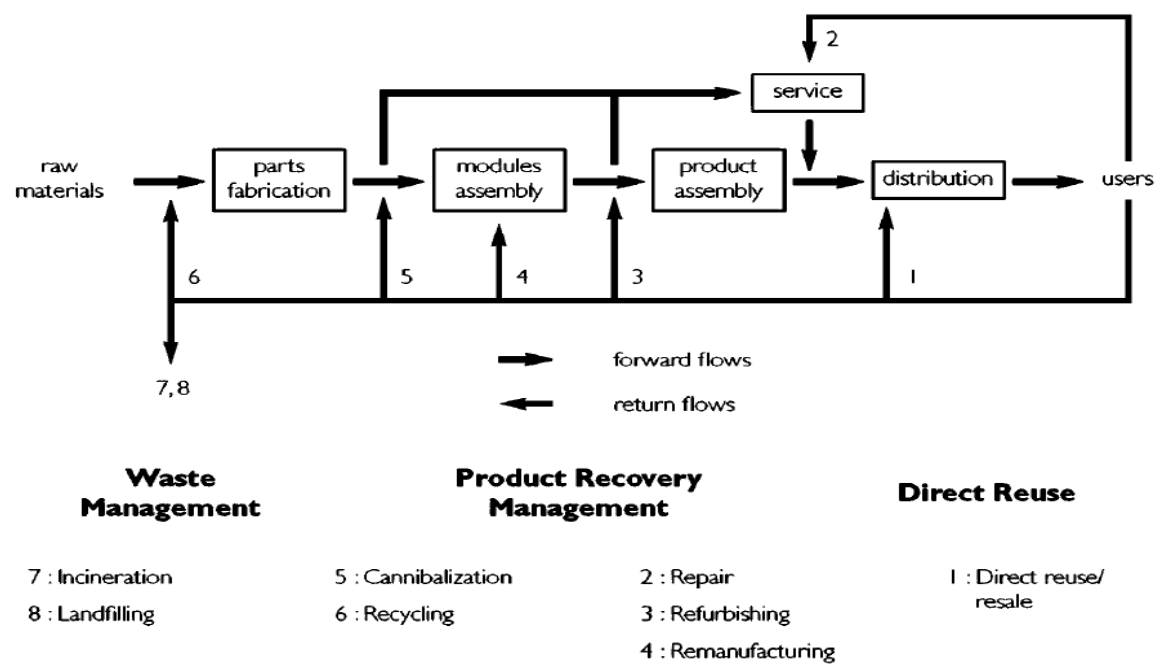

Figure 1. Schematic diagram of product production and recycling. (Data source: Thierry M., Salomon M., Van Nunen J., Van Wassenhove L. (1995) [1]). 
The impact of environmental responsibility on the manufacturing business model is becoming higher and higher, and the products produced by different industries have different environmental loads. Moreover, the life of the product will vary with the frequency of use or the environment, resulting in differences in surface luminosity, short circuit, damage, or scrapping process. Products produced in different industries have different environmental hazards and different levels of recycling. This study considers different recycling levels for a single project as shown in Figure 1 (Thierry, M., et al. (1995) [1]). In other words, the recycling status can be roughly divided into transfer, polishing, maintenance, remanufacturing, crushing, burying, incineration.

Due to the different attributes of various products, the degree of recycling treatment is also different. Some products do not even have maintenance or remanufacturing operations. Therefore, the various process levels and recovery types are summarized in Table 1.

Table 1. Reverse logistics processing and recovery type.

\begin{tabular}{ccc}
\hline Processing Level & Recovery Type & Example \\
\hline Repairing (Refresh) & Used/second hand & Steam locomotive, etc. \\
Remanufacturing (Reproduction) & Element/components & Electronic parts \\
Recycling (Reuse) & Raw material & Iron, plastic pellets \\
Disposal & Waste residue & Waste slag \\
\hline
\end{tabular}

The symbol definitions are shown below:

Symbol definition:

$\lambda \mathrm{i} \quad$ Stage i repair or remanufacturing rate;

$\gamma \mathrm{i} \quad$ Stage i recovery rate;

$\mathrm{Vi} \quad$ The degree of different influencing factors;

W influence factor weight;

E Recursive probability matrix;

s Safety stock:

Q Inventory (Economic order quantity);

$\mathrm{P}_{\mathrm{i}} \quad$ Stage I probability;

R Order maintenance items;

$\mathrm{L}_{\mathrm{i}} \quad$ Expected number of each recycling level i system;

$\theta \quad$ Lagrangian Correction factor;

h holding cost;

$\pi \quad$ setup cost;

$\tau \quad$ lead time;

A unit cost.

\section{Mathematical Model}

3.1. Using Group Decision Support System (GDSS) and Fuzzy Matrix to Determine the Fuzzy Classification Principle for the Corresponding Recycling Rating

In this study, we assumed that there were $t$ recycle processing levels. We first used a group decision support system (GDSS) as the measurement procedure to determine the test standard, $C=\left\{c_{1}, \ldots c i\right\}$, the test standard items. The recycling score was expressed as a full score of 100 points, and the rating given for each recycling level was $M^{\prime}=\left\{m_{i 1}, \ldots, m_{i n}\right\} ; m_{i j} \in\{0,100\},(i=1, \ldots, t ; j=1, \ldots, n)$. $\mathrm{m}_{i j}$ denotes the subjective weight of a group of experts. It represents an integer value between 0 to 100 for the weight of experts. The experts from different recycling sites will use the fuzzy matrix from $[0,100]$ generating a rating score of the recycling manufacturer, and then use the GDSS to select the test standard.

We assumed $t$ as the recycle processing levels (input), each of which had a different degree of influence factor $\left(u_{i}\right), u_{i}=\{1 \sim 100\}$ where $u_{i}$ represents the actual use status of different impact factors 
(degree of damage, processing costs and the number of miles traveled). The results were standardized from 1 to 100. $\mu_{g i}\left(m_{i}^{\prime}\right)$ denotes the average rating score from the experts of different recycling sites. We used $\left(\mu_{g 1}\left(m_{i}^{\prime}\right), \mu_{g 2}\left(m_{i}^{\prime}\right), \ldots, \mu_{g d}\left(m_{i}^{\prime}\right)\right)=$ AHP/ $\mathbf{u}_{\mathrm{i}}$ or the GDSS model to build a fuzzy matrix. We used AHP level analysis to divide by different impact factors (ui), in order to carry out the standardization procedure, and the result obtained was the standardized comparative matrix. To calculate of the fuzzy matrix, we determined the fuzzy classification principle, which was then able to correspond to the final rating of the recovery. By simplified conversion procedures, we used $\left(e_{i 1} \ldots \ldots e_{i d}\right)$ instead of $\left(\mu_{g 1}\left(m_{i}^{\prime}\right), \mu_{g 2}\left(m_{i}^{\prime}\right), \ldots, \mu_{g d}\left(m_{i}^{\prime}\right)\right)$ to simplify the formula, as shown in Equation (1):

$$
E=\left[\begin{array}{cccc}
e_{11} & e_{12} & \ldots & e_{1 d} \\
e_{21} & e_{22} & \ldots & e_{2 d} \\
\ldots & \ldots & \\
\mathrm{e}_{\mathrm{n} 1} & e_{n 2} & \ldots & e_{n d}
\end{array}\right]=\left(e_{i j}\right)_{(i=1,2, \ldots \mathrm{n} ; j=1,2, \ldots \mathrm{d})}
$$

For the analysis, we defined the weight of each influencing factor as $\widetilde{W}=\left\{\frac{w_{1}}{u_{1}}, \ldots . ., \frac{w_{t}}{u_{t}}\right\} ; \sum_{i=1}^{t} w_{i}=1$, and $\widetilde{P}=\left\{u_{1}, \ldots . ., u_{t}\right\}$ represented a set of fuzzy influencing factors. The rating of each recycling level was expressed as $1-100$, and these scores were assigned back to the corresponding test standard items. For example, $\widetilde{W}=\left\{\frac{0.5}{\text { Degree of damage }}, \frac{0.3}{\text { Processing costs }}, \frac{0.2}{\text { mileages }}\right\}=\left\{\frac{0.5}{1 \ldots 100}, \frac{0.3}{1 \ldots 100}, \frac{0.2}{1 \ldots 100}\right\}$; finally, we got the Equation (2), as shown below:

$$
Y=W \times E=\left(w_{1} w_{2} \ldots w_{n}\right) \times\left[\begin{array}{cccc}
e_{11} & e_{12} & \ldots & e_{1 d} \\
e_{21} & e_{22} & \ldots & e_{2 d} \\
\ldots & \ldots & \\
e_{\mathrm{n} 1} & e_{n 2} & \ldots & e_{n d}
\end{array}\right]
$$

We standardized from the evaluation of the $Y$ vector, determining the fuzzy classification principle $y_{i}=\max \left(y_{1} \ldots y_{d}\right)$, which was able to correspond to the final rating of the recovery.

\subsection{An Inventory System with Multiple-Processing Levels and Multiple-Period Returns}

Comparing our system to the single-item system (Figure 2) by Erwin et al. [19], we developed approximation procedures of multiple-processing levels and multiple-period returns (Figure 3) to show the effects of different recycling levels on inventory cost.

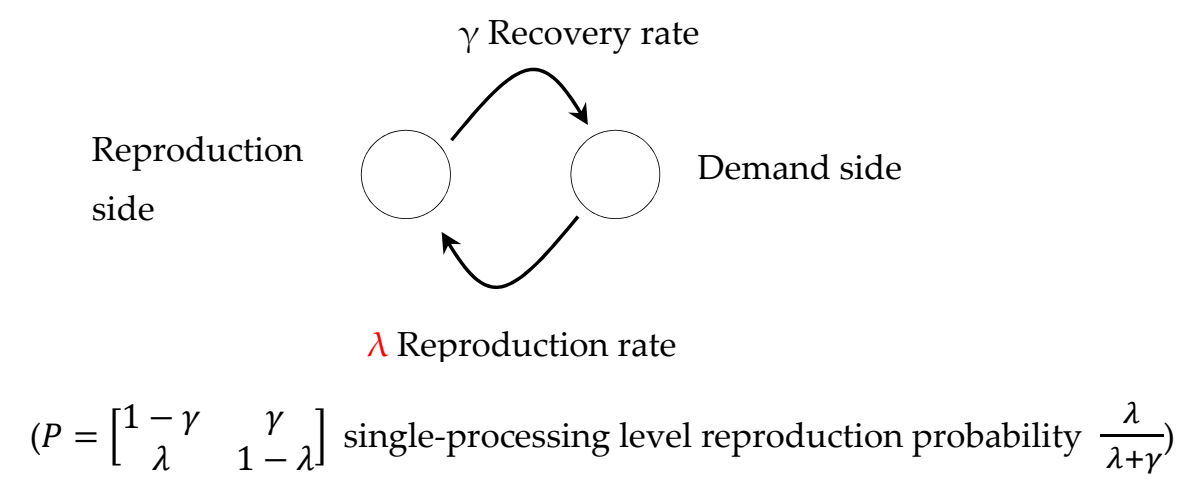

Figure 2. The recycling transfer graph with single-processing level return.

In practice, product recycling will change its characteristics over time, so we assumed the time point $\{t \in T\}$ (where $T$ was the set of time points), and let $X_{t}$ be the recovery state of the system at $t$. In most cases, although we did not know the certain value of the recovery state of the system at time $t$, it was a random variable, and a random recovery process $\left\{X_{t}\right\}$ had the Markov property, $\operatorname{Pr}\left(X_{t+1}=j \mid X_{t}\right.$ $\left.=\mathrm{i}, \mathrm{X}_{\mathrm{t}-1}=\mathrm{I}-1, \mathrm{X}_{\mathrm{t}-2}=\mathrm{i}-2, \mathrm{X}_{\mathrm{t}-3}=\mathrm{i}-3, \ldots . ., \mathrm{X}_{0}=0\right)=\mathrm{P}_{\mathrm{r}}\left(\mathrm{X}_{\mathrm{t}+1=\mathrm{j}} \mid \mathrm{X}_{\mathrm{t}}=\mathrm{i}\right)$, to calculate the inventory level with a continuous time Markov chain (Pawel et al. (2019) [20]). 


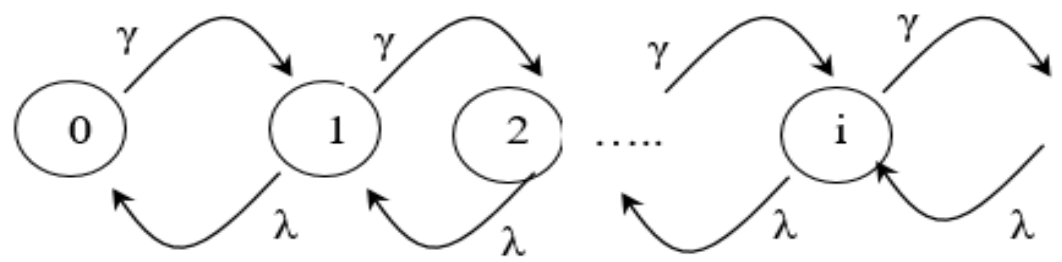

$P_{0}=1-\frac{\gamma}{\lambda^{\prime}} P_{i}=\left(\frac{\gamma}{\lambda}\right)^{i}\left(1-\frac{\gamma}{\lambda}\right)$ and the expected number of recycling systems L equals $\frac{\gamma}{\lambda-\gamma}$

Figure 3. The recycling transfer graph with multiple-period returns.

Demand reduced the inventory level. When the inventory reached safety stock s, it would directly increase the inventory level to $s+Q$. Recycling increased the inventory level and the Markov chain was ergodic if the $\lambda$ reproduction rate $<\gamma$ recovery rate, and the central limit distribution of the inventory level tended to be a stable distribution (Erwin et al. [19]).

From the cyclic transfer process shown as Figure 4, we could develop the Markov chain long-term stability matrix, as shown in Equation (3) (Yousif et al. (2020) [21]), which considered the continuous transfer, and the expansion and transfer, of the previous period and the next period.

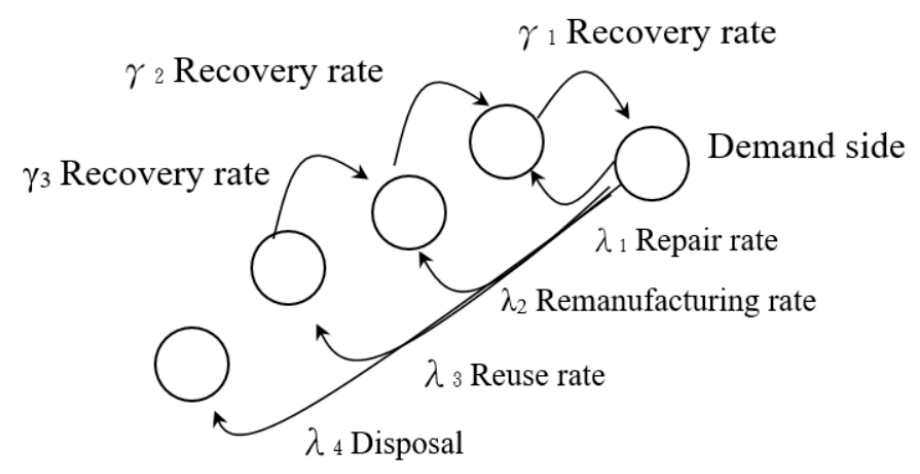

Processing side

Figure 4. Recycling transfer graph with multiple-processing level returns.

Products were scrapped under long-term stability, P equals

$$
P=\left[\begin{array}{ccccc}
1-\sum \gamma_{i} & \gamma_{1} & \gamma_{2} & \gamma_{3} & \gamma_{4} \\
\lambda_{1} & 1-\lambda_{1} & 0 & 0 & 0 \\
0 & \lambda_{2} & 1-\lambda_{2} & 0 & 0 \\
0 & 0 & \lambda_{3} & 1-\lambda_{3} & 0 \\
0 & 0 & 0 & \lambda_{4} & 1-\lambda_{4}
\end{array}\right]
$$

From Figure 4, we expanded the single-item single-location inventory system to the multiple-period, multiple-processing level inventory system under different safety stocks (s) and different inventory levels $(\mathrm{Q})$, as shown in Figure 5.

After the inventory levels of different items in different periods went through the Markov cycle conversion process during $\mathrm{n}$ items $\mathrm{r}$ recycle, they gradually converged to form a steady-state inventory level function $\mathrm{I}(\mathrm{T})$, (that is, $\left.\overrightarrow{\mathrm{I}}^{n}(t)+\overrightarrow{\mathrm{I}}^{\prime}(t)=I(t)+k\right)$ so that after an indefinite Markov conversion, the expected inventory level was as follows; $k$ was constant, $E\left(I_{i}(\infty)\right)=\left(s+1+\frac{Q-1}{2}+L_{i}\right), L_{i}$ was the expected number of systems for each recycling level i. 


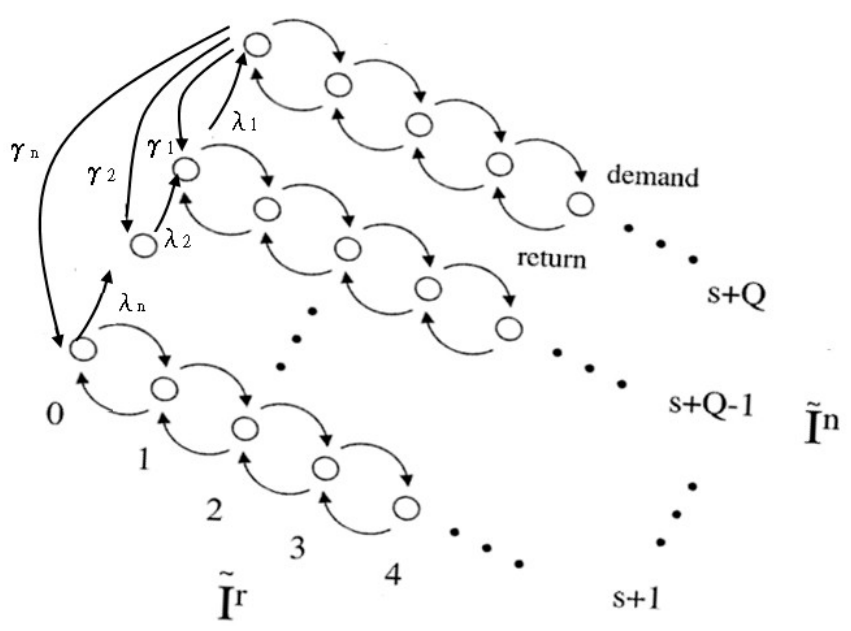

Figure 5. Recycling transfer graph with multiple-processing levels and multiple-period returns.

According to Erwin et al. [19], before the expected replenishment quantity is filled, $\mathrm{F}(\mathrm{s}, \tau)$ represents the average value $\mu \tau=(\lambda-\gamma) \tau$ and variance $\sigma \tau=(\lambda-\gamma) \tau$ of the expected excess demand exceeding the normal distribution s-R. The $(\lambda-\gamma) / Q$ denotes the average order quantity per unit time, so the average order cost is equal to $\mathrm{A}(\lambda-\gamma) / \mathrm{Q}$. We can also get the total cost function, $\mathrm{K}(\mathrm{s}, \mathrm{Q})$; if converted into the average order quantity per unit time of each recycling processing station, $\frac{\mathrm{L}}{\gamma Q}$, the average order cost is equal to $\mathrm{A}\left(\frac{\mathrm{L}_{\mathrm{i}}}{\gamma_{i} Q}\right)$. The revised total cost function is shown below in Equation (4).

$$
\mathrm{K}(\mathrm{s}, \mathrm{Q})=\mathrm{A}\left(\frac{\mathrm{L}}{\gamma Q}\right)+(\pi+\mathrm{h}) \frac{F(s, \tau)^{2}}{2 Q}+\mathrm{h}\left[\left(\mathrm{s}+1+\frac{Q-1}{2}+\mathrm{L}\right)-\mathrm{R}-\left(\frac{\mathrm{L}}{\lambda}\right) \tau\right]
$$

Assuming that the resource limits for all kinds of recycling processes are the same, the equation is as follows:

$$
\mathrm{Qi} *=\sqrt{\frac{\pi+h}{h} F(s *, \tau)^{2}+\frac{2 \gamma A}{h \mathrm{~L}_{\mathrm{i}}}}
$$

Assuming that all resource limits for various recycling processes are different, the following equation is obtained using the Lagrangian function:

$$
\mathrm{Qi} *=\sqrt{\frac{F(s *, \tau)^{2}(\pi i+h i)+2\left(\frac{\gamma_{i}}{\mathrm{Li}}\right) A i}{h i+2 \theta w i}}
$$

$\sum_{i=1}^{n} w i Q i *=W($ resource limits $), \theta$ is the correction factor of the Lagrangian.

This leads to another total cost function of $\mathrm{K} 2(\mathrm{~s}, \mathrm{Q})$. Using the approximate value, the optimal Qi* (Equation (7)) value of the various inventory of different recycling processes are calculated as follows:

$$
\mathrm{Qi} *=\sqrt{\left((\pi+h) \int_{0}^{\tau} F(s *, \tau) d t+A\right) \frac{2 \gamma}{h \times L i}}
$$

The Qi * value of different resource limits for various kinds of inventory for different recycling processes is calculated as follows. The model is shown (Equation (8)) and the optimal value for $S$ is shown (Equation (8)):

$$
\mathrm{Qi} *=\sqrt{\left((\pi+h) \int F(s *, \tau) d t+A\right) \frac{2 \gamma}{h \times L i+2 \theta w i}}
$$


$\sum_{i=1}^{n} w i Q i *=W($ Resource limit), $\theta$ is the Lagrangian correction factor,

In addition, $\mathrm{s}^{*}$ is the optimal value for $\mathrm{S}$, which must meet:

$$
-\sqrt{\frac{d F(s, t)}{d s}}=\frac{h}{\pi+h} \cdot \frac{\operatorname{LiQ}}{\gamma}
$$

Muckstadt and Sapra (2010) [22] roughly estimated that the net inventory is normally allocated. Here, they determined the steady-state inventory level and demand and the time before the repair station output is short. Consequently, they acquired different equations for the expected replenishment quantity. The drawback of their analysis is that the net inventory has asymptotic characteristics, which sometimes do not conform to actual behavior.

If Erwin [19] compares the desired demand value to $\lambda$ and the recovery flow expectation value $\gamma$, the expected value of the expected recovery flow rate corresponding to only the correct demand flow rate is $\lambda-\gamma$. Obviously, the uncertain recovery flow rate will increase the cost and height handle of the variability process. Moreover, when $\gamma$ tends to $\lambda$, the average cost will tend to be infinite. Reducing this surge in total cost is a waste strategy to reduce the recovery rate.

\section{Numerical Analysis}

In view of the fact that various products do not have a recycling grade, and the product recycling grade process mechanism and its recycling grade are not easy to judge from their appearance, this article takes the car as an example, divides the car recycling grade into four grades, and uses a group decision support system (GDSS) as a measurement procedure and fuzzy matrix calculation. The preliminary results of the comparison of 20 vehicles from the sale of second-hand cars, car repair shops to decomposition sites are suggested to use different clusters of vehicles and categorize each vehicle's recycling data in different processing sites.

The test standard items generated by GDSS, the results are seven major items, $C=$ \{mileage, processing cost, damage degree, vehicle age, processing time, speed performance, functionality\}

According to their preferences, experts in various fields (sales, car repairs, dismantling of parts, scrapping) will use the $[0,100]$ fuzzy method to score the car for recycling. After the GDSS calculation, for the resulting preference vector $\mathrm{u}, \mathrm{u}=(0.97,0.972,0.98,0.81,0.832,0.32,0.182)$. Next, the three main popular test standards were selected, and the set was changed to $C=\{$ damage, processing cost, mileage\}. In order to establish the above semantic and discriminatory issues, according to the opinions of experts in various automobile recycling yards, the following guidelines were formulated for the process of automobiles (Table 2).

Table 2. Guidelines for the process of automobiles.

\begin{tabular}{ccccc}
\hline Item & Repair & Remanufacture & Recycling & Disposal \\
\hline Level of damage & $\mathrm{L}(1 \sim 33)$ & $\mathrm{L}(1 \sim 33)$ & $\mathrm{M}(34 \sim 67)$ & $\mathrm{H}(68 \sim 100)$ \\
Processing costs & $\mathrm{L}$ & $\mathrm{M}, \mathrm{H}$ & $\mathrm{L}, \mathrm{M}$ & $\mathrm{L}, \mathrm{M}, \mathrm{H}$ \\
Mileage & $\mathrm{L}$ & $\mathrm{M}$ & $\mathrm{M}, \mathrm{H}$ & $\mathrm{H}$ \\
\hline
\end{tabular}

Then, the important scores of 1 9 were compared to each other to get the comparison relationship matrix (shown below):

$$
\mathrm{AHP}=\left[\begin{array}{ccccc}
1 & 1 & 1 / 3 & 4 & 5 \\
1 & 1 & 1 / 3 & 5 & 5 \\
3 & 3 & 1 & 7 & 7 \\
1 / 4 & 1 / 5 & 1 / 7 & 1 & 1 / 3 \\
1 / 5 & 1 / 5 & 1 / 7 & 3 & 1
\end{array}\right]
$$


Then, we calculated the relevant weight through GDSS (normalized), got $W=(0.205502,0.214881$, $0.475251,0.042013,0.062352)$, and $W_{1}+W_{2}+W_{3}+W_{4}+W_{5}=1$. In the rating part, it was divided into four levels: D: disposal, S: reuse, R: remanufacture, E: repair. The membership function was defined as follows:

$$
\begin{gathered}
\mu D(u)=\left\{\begin{array}{cc}
1 & 0 \leq u \leq 55 \\
(60-u) / 5 & 55<u \leq 60 \\
0 & 60<u \leq 100 \\
\mu \mathrm{S}(u)=\{ & \mu \mathrm{R}(u)=\left\{\begin{array}{cc}
0 & 0 \leq u \leq 70 \\
(u-70) / 5 & 70<u \leq 75 \\
1 & 75<u \leq 80 \\
(85-u) / 5 & 80<u \leq 85 \\
0 & 90<u \leq 100
\end{array}\right. \\
(u-60) / 5 & 00<u \leq 65 \\
1 & 65<u \leq 70 \\
(80-u) / 10 & 70<u \leq 80 \\
0 & 80<u \leq 100
\end{array}\right.
\end{gathered}
$$

The established weights for triangular fuzzy numbers input variables input1, input2, input3, respectively, indicate the degree of damage, processing cost, mileage, and output indicates the classification of the recycling process shown in Figure 6.

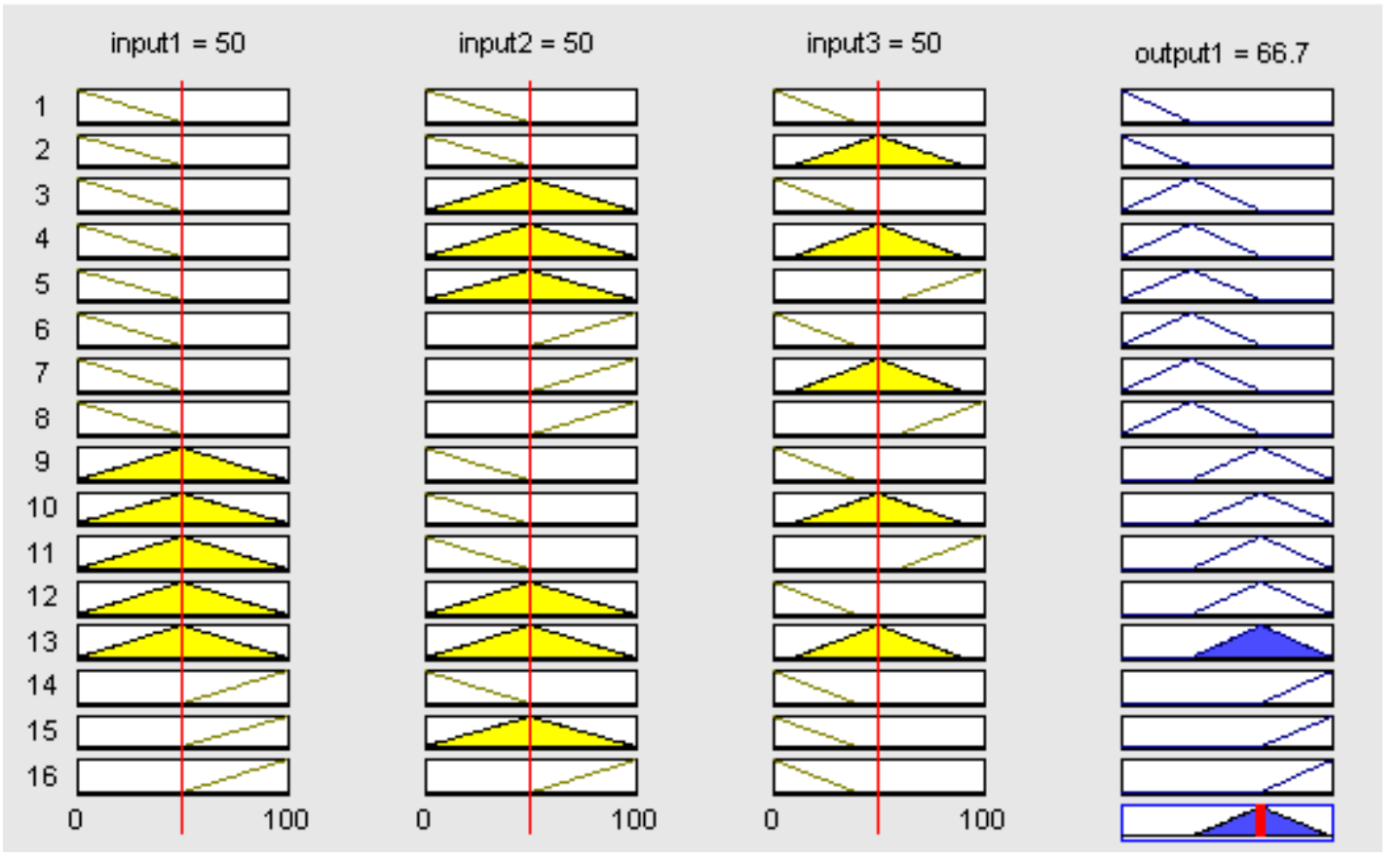

Figure 6. Triangular fuzzy number graphs.

Assuming that each car is scored by experts and scholars, the following matrix (E) shows the test results obtained by the car.

$$
E=\left[\begin{array}{cccc}
0.06 & 0.8 & 0.14 & 0 \\
0 & 0.74 & 0.26 & 0 \\
0 & 0.94 & 0.06 & 0 \\
0 & 0 & 1 & 0 \\
0 & 0 & 0.3 & 0.7
\end{array}\right]
$$


Using the weights obtained before, the result of calculating the vector yi takes the maximum value, and maps to each level to correspond to which grade the product should be; the mark value is shown below.

$$
\begin{aligned}
Y & =W \times E=(0.205502,0.214881,0.475251,0.042013,0.062352) \times\left[\begin{array}{cccc}
0.06 & 0.80 & 0.14 & 0 \\
0 & 0.74 & 0.26 & 0 \\
0 & 0.94 & 0.06 & 0 \\
0 & 0 & 1 & 0 \\
0 & 0 & 0.3 & 0.7
\end{array}\right] \\
& =(0.01233,0.770150,0.173873,0.043647)
\end{aligned}
$$

$Y$ is a vector matrix, representing y1, y2, y3, y4 (Repairing, Remanufacturing, Reuse, Disposal, respectively). $Y$ is the final corresponding evaluation score obtained through the fuzzy classification results; where $\mathrm{y} 2$ is the highest evaluation score, which means that the product Remanufacturing has the highest relative importance. Finally, the obtained product is y2, and the corresponding grade is R, which means that the car should be listed as reuse.

In addition, in Figure 7 shown below, Input1 and Input2, respectively, indicate the degree of damage and processing cost that affect the output recovery processing level.

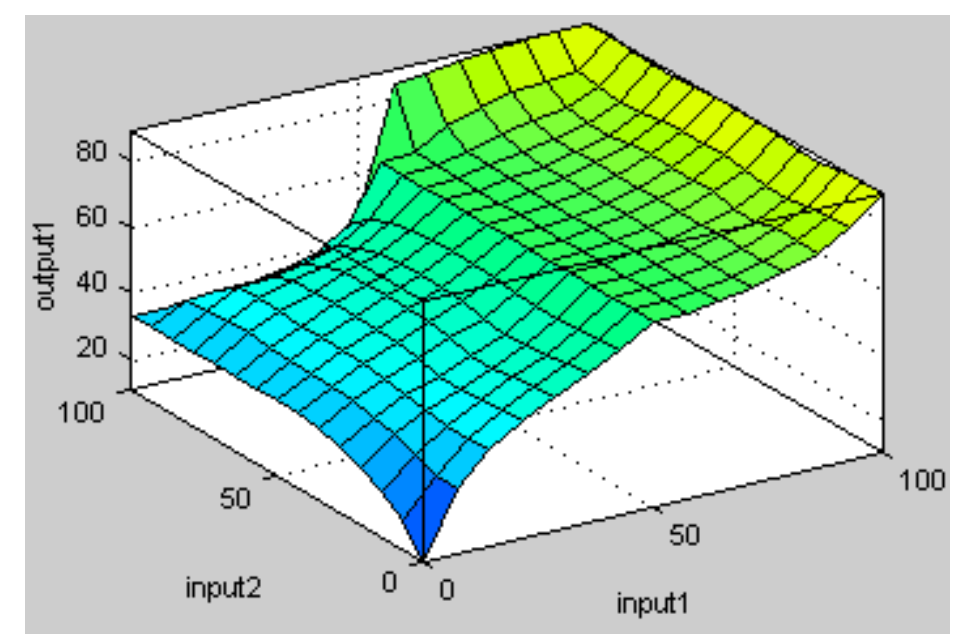

Figure 7. Hyper surface.

Next, we used Matlab software to show the single-item, single-location inventory system by Erwin et al. (1996) and assumed that if the holding cost $\mathrm{h}$ is 1 , then the $\operatorname{cost} \lambda=1$, the unit $\operatorname{cost} \mathrm{A}=10$, the setting $\operatorname{cost} \pi=10$ and the pre-processing time $\tau=10$. A trend chart of total inventory cost is shown in Figure 8 .

We used the parameters derived from fuzzy theory (disposal, reuse, remanufacture, repair) = $(0.012330,0.770150,0.173873,0.043647)$ in the inventory formula Equation (9). Figure 9 shows a trend chart of total inventory cost of different levels of recovery rates.

In reverse logistics, the total cost of scrap is the lowest, and the total cost of reused will be the highest. Next, we conducted sensitivity analysis for four levels of recovery rates.

In addition, for each parameter of the system, a sensitivity analysis was performed on each parameter in the system to discuss the impact of each parameter change on the total cost per unit time. These parameters included the average recovery rate, the inventory holding cost of the manufacturing center, the inventory holding cost of the recycling processing center, the order cost of the manufacturing center, the setting cost of the recycling processing center, the purchase cost of the manufacturing center and the recycling center.

We applied Mathematica5.0 software to bring the numerical examples into the formula, and used the Find minimum command to find the best order batch $Q_{m}$ and the best recycling remanufacturing 
batch $Q_{r}$, then took the integer value, using the rounding method, to calculate the minimum total cost per unit time. The recovery rate $\gamma$ is random, $\gamma=1 / \lambda$, and $\gamma<\lambda$, $\lambda$ follows the exponential distribution, and we know that $\gamma>1 / \lambda$.

Best Recycling Inventory

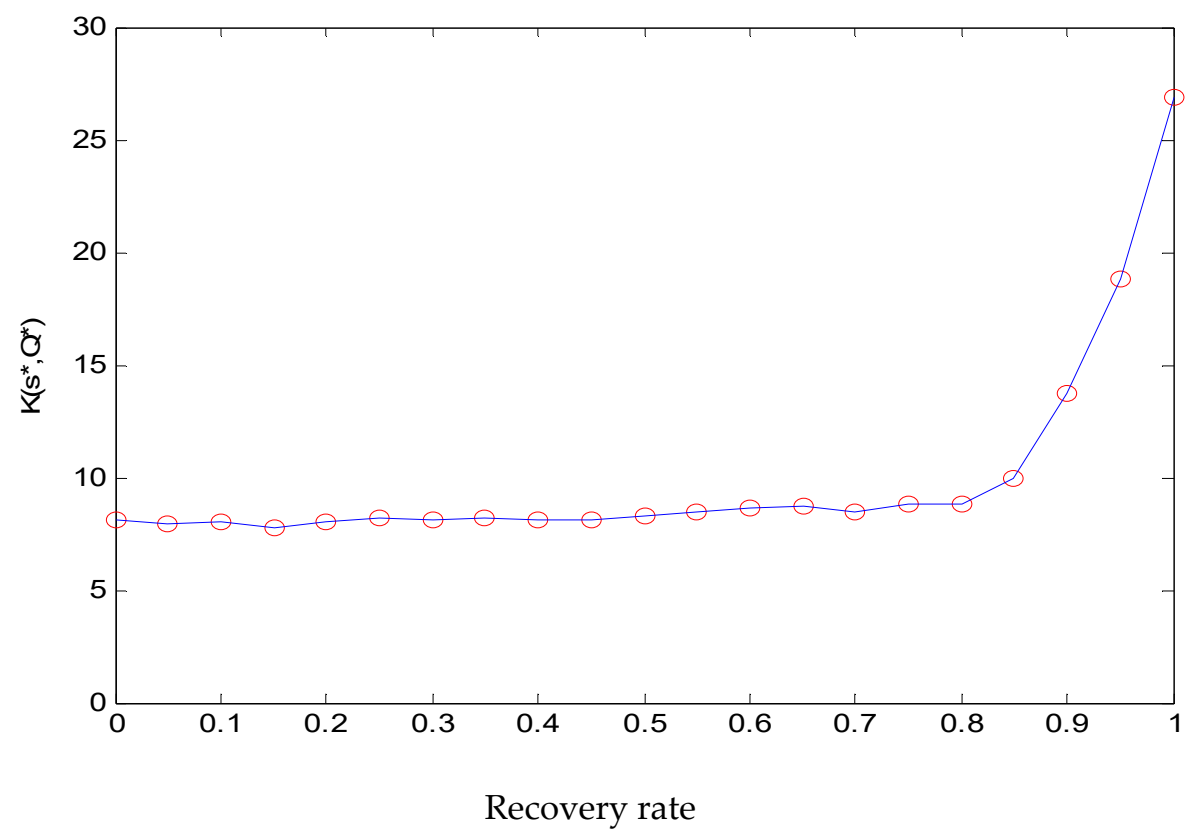

Figure 8. Graph of change in unit cost of recovery rate.

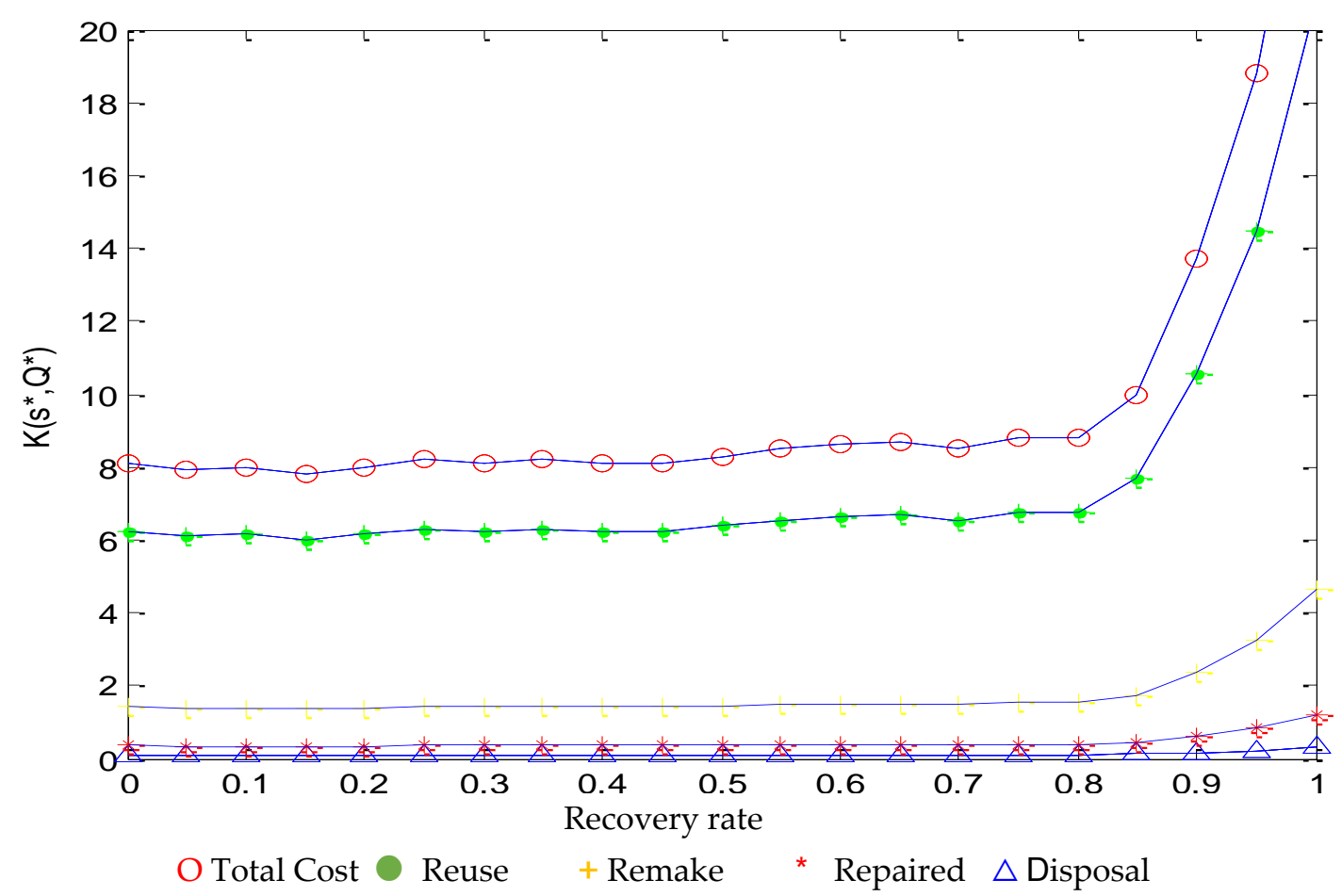

Figure 9. Unit price chart integrating different levels of recovery rates.

The data of this research example are: the demand per unit time $\lambda$ is 10 , the average recovery per unit time $\gamma$ is 8 , the manufacturing center's order cost per unit time is 200, the manufacturing center's inventory holding cost per unit time is 1 , the manufacturing center's purchase cost per unit time is 10 , 
and the recycling processing center's setup cost per unit time is 500 . The inventory holding cost per unit time of the recycling processing center is 1 , and the cost per unit time of the recycling processing center is 10 .

Bringing the aforementioned data into the formula, the best order batch size of the manufacturing center is 99 , the best manufacturing batch size of the recycling processing center is 59 , and the best total cost is 306.321. It is divided into 3D graphics as shown in Figure 10.

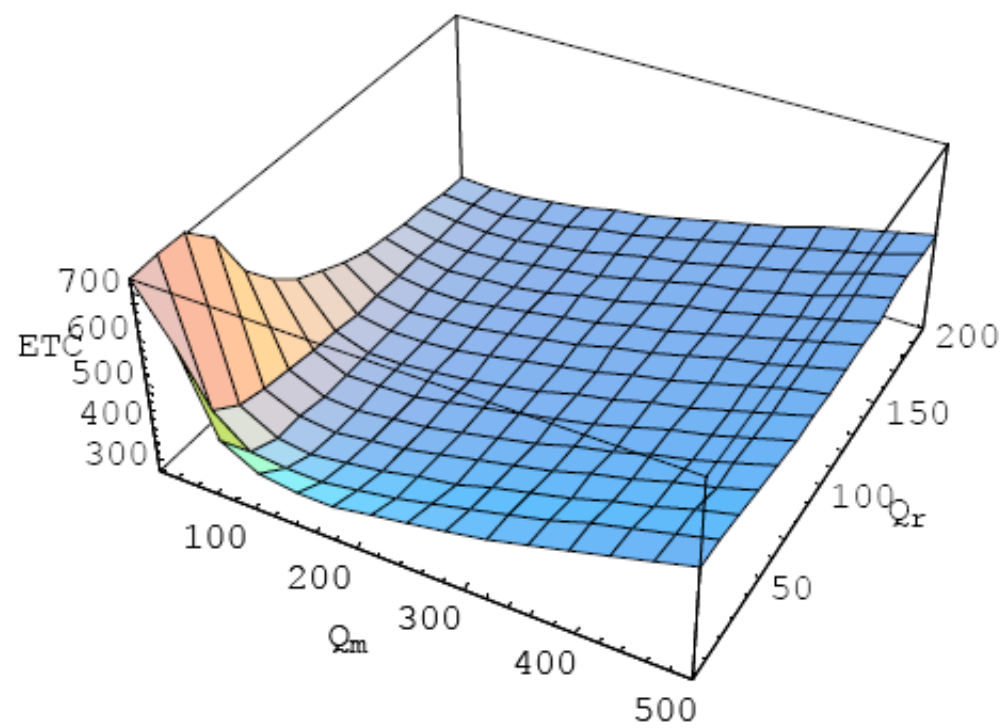

Figure 10. Manufacturer and remanufacturer order batch change chart.

For the analysis of $Q_{m}$ and $Q_{r}$, when the remanufacturing batch $Q_{r}$ of the recycling processing center is 10, the order batch, $Q_{m}$, is 75 and the minimum ETC value is 494.603 . We can see the changes in Qm and ETC in Figure 10. Conversely, when the manufacturing center's order batch $\mathrm{Q}_{\mathrm{m}}$ is set to 80, the remanufacturing batch, $Q r$, is 58 and the minimum ETC value is 348.07. The changes in $Q_{m}$ and ETC can be seen in Figures 11 and 12 .

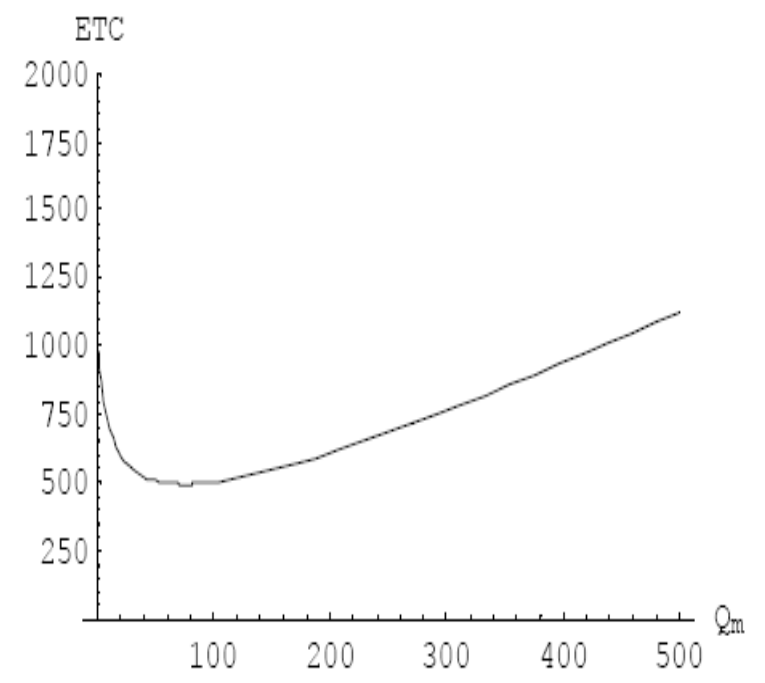

Figure 11. Manufacturers ordering batches total cost change chart. 


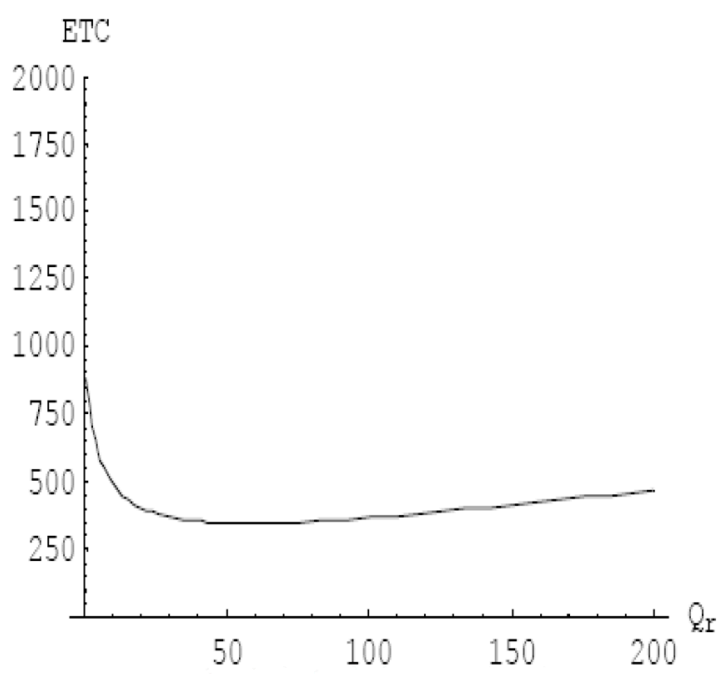

Figure 12. Remanufacturer order batches total cost change chart.

From the above solution, it shows that the inventory strategies proposed by this study can reach the minimum total cost per unit time, the best order batch of the manufacturing center and the best remanufacturing batch of the recycling processing center.

\section{Conclusions}

The method presented in this article is to use the Fuzzy Set method to determine the main impact on the recovery process and its corresponding weight, then use AHP to determine the relationship between the recovery and processing levels. The GDSS system has also been developed to support such measurement methods and procedures. The method proposed in this article is compared with the GDSS system that promotes recycling. It also provides a convenient way for recyclers or manufacturers to sort their own products and use fuzzy numbers to select a set of test standards. In the operation description section of the fuzzy set, this article uses the variable code in the formula to investigate the recycler's product level. In the evaluation process of this method, there are still some errors in the evaluation from the recycling processor, but if there are more experts to evaluate and define, the classification criteria will be clearer, and the recovery processing situation obtained will be more accurate.

We integrate the inventory control model at the recovery process level. Although the analysis model is quite accurate, the higher the recovery rate is, the more difficult the recovery rate and the remanufacturing rate are. It is not easy to determine the related recovery rate; however, we first define and calculate the probability of each recovery process level by the fuzzy theoretical limit, which is conducive to findings that are more in line with the actual inventory model and total cost. Abandonment is still a necessary decision in this study, because the change in the recovery rate will increase the inventory level and the total cost. We find that if the recovery rate is more than $90 \%$, the cost of processing and recovery will be more than doubled. This study also finds the minimum total cost per unit time, the best order batch size of the manufacturing center and the best remanufacturing batch size of the recycling processing center.

Besides, the green circular economy and corporate responsibility awareness are becoming more and more important. In addition to the government's green supply chain counseling policy, an authentication mechanism for corporate responsibility of upstream and downstream manufacturers for recycling is also required, so that the recycling rate of defective products can reach $100 \%$ recycling as soon as possible.

For further study, we suggest that the internal value of the model can be understood from more complex production scenarios, and that government policies for recycling subsidies and good green enterprise certification among manufacturers should be taken into account. The reverse supply chain to recycle and process the recycled products into rebirths should be encouraged, and should induce the 
final product manufacturers in the forward supply chain to increase the purchase of rebirths, so that the operation of the color supply chain can be more efficient.

Author Contributions: Conceptualization, C.-C.L.; methodology, C.-C.L., T.-F.H.; software, C.-C.L., C.-L.L., validation, C.-C.L., C.-L.L., formal analysis, C.-L.L., investigation, T.-F.H.; C.-L.L., resources, T.-F.H.; data curation, C.-C.L., T.-F.H.; writing-original draft preparation, C.-C.L., T.-F.H.; writing-review and editing, C.-C.L., C.-L.L., visualization, C.-C.L., T.-F.H., C.-L.L., supervision, T.-F.H.; project administration, T.-F.H.; funding acquisition, T.-F.H.; All authors have read and agreed to the published version of the manuscript.

Funding: This research was funded by the Ministry of Science and Technology, Taiwan, under NO. MOST 108-2622-E-167-013-CC3.

Acknowledgments: The research team is thankful for the funding support from the Ministry of Science and Technology, Taiwan, under NO. MOST 108-2622-E-167-013-CC3.

Conflicts of Interest: The authors declare no conflict of interest.

\section{References}

1. Thierry, M.; Salomon, M.; Van Nunen, J.; Van Wassenhove, L. Strategic issues in product recovery management. Calif. Manag. Rev. 1995, 37, 114-135. [CrossRef]

2. Fleischmann, M.; Jacqueline, M.B.-R. Quantitative models for reverse logistics: A review. Eur. J. Oper. Res. 1997, 103, 1-17. [CrossRef]

3. Carter, C.R.; Ellram, L.M. Reverse Logistics: A review of the literature and framework for future investigation. J. Bus. Logist. 1998, 19, 85-102.

4. Guide, V.D.R.; Van Wassenhove, L. The reverse supply chain. Harv. Bus. Rev. 2002, 80, $25-26$.

5. Zadeh, L.A. Outline of a new approach to the analysis of complex systems and decision processes. IEEE Trans. Syst. Man Cybern. 1973, 1, 28-44. [CrossRef]

6. Jang, J.-Y.R.; Sun, C.-T.; Mizutani, E. Neuro-Fuzzy and Soft Computing: A Computational Approach to Learning and Machine Intelligence; Prentice Hall: New Jersey, NJ, USA, 1996.

7. Zipkin, P. Mortgages and Markov chains: A simplified evaluation model. Manag. Sci. 1993, 39, 683-691. [CrossRef]

8. Aase, K.K. A Markov model for the pricing of catastrophe insurance futures and spreads. J. Risk Insur. 2001, 68, 25-49. [CrossRef]

9. Ching, W.K.; Fung, E.S.; Ng, M.K. A multivariate Markov chain model for categorical data sequences and its applications in demand predictions. IMA J. Manag. Math. 2002, 13, 187-199. [CrossRef]

10. Naranjo, L.; Pérez, C.J.; Fuentes-García, R.; Martín, J. A hidden Markov model addressing measurement errors in the response and replicated covariates for continuous nondecreasing processes. Biostatistics 2019, 1-15. [CrossRef] [PubMed]

11. Naranjo, L.; Luz, J.; Esparza, R.; Pérez, C.J. A Hidden Markov Model to Address Measurement Errors in Ordinal Response Scale and Non-Decreasing Process. Mathematics 2020, 8, 622. [CrossRef]

12. Lin, C.-C.; Lin, C.-W. Defective item inventory model with remanufacturing or replenishing in an integrated supply chain. Int. J. Integr. Supp. Manag. 2011, 6, 254-269. [CrossRef]

13. Lin, C.-C.; Su, C.-T. Inventory model for the batch processing of defective products in manufacturing and remanufacturing. Adv. Mater. Res. 2013, 756-759, 4604-4611. [CrossRef]

14. Verhoeven, P.; Sinn, F.; Herden, T.T. Examples from Blockchain Implementations in Logistics and Supply Chain Management: Exploring the Mindful Use of a New Technology. Logistics 2018, 2, 20. [CrossRef]

15. Ho, T.-F.; Lin, C.-C.; Lin, C.-L. Determining the Optimal Inventory and Number of Shipments for a Two-Resource Supply Chain with Correlated Demands and Remanufacturing Products Allowing Backorder. Mathematics 2020, 8, 548. [CrossRef]

16. Minner, S.; Kiesmüller, G.P. Dynamic product acquisition in closed loop supply chains. Int. J. Prod. Res. 2012, 50, 2836-2851. [CrossRef]

17. Zhang, X.; Zhao, G.; Qi, Y.; Li, B. A robust fuzzy optimization model for closed-loop supply chain networks considering sustainability. Sustainability 2019, 11, 5726. [CrossRef] 
18. Govindan, K.; Mina, H.; Esmaeili, A.; Mohamma, S.; Gholami-Zanjani, S.M. An integrated hybrid approach for circular supplier selection and closed loop supply chain network design under uncertainty. J. Clean. Prod. 2020, 242, 1183172. [CrossRef]

19. Van der Laan, E.; Dekker, R.; Salomon, M.; Ridder, A. An (s, Q) inventory model with remanufacturing and disposal. Int. J. Prod. Econ. 1996, 46, 339-350. [CrossRef]

20. Wiecek, P.; Kubek, D.; Aleksandrowicz, J.; Strózek, A. Framework for onboard bus comfort level predictions using the markov chain concept. Symmetry 2019, 11, 755. [CrossRef]

21. Alyousifi, Y.; Othman, M.; Sokkalingam, R.; Faye, I.; Petronio, C.L.S. Predicting daily air pollution index based on fuzzy time series markov chain model. Symmetry 2020, 12, 293. [CrossRef]

22. Muckstadt, J.A.; Sapra, A. Principles of Inventory Management: When You Are Down to Four, Order More; Springer: New York, NY, USA, 2010; ISBN 978-0-387-24492-1.

(C) 2020 by the authors. Licensee MDPI, Basel, Switzerland. This article is an open access article distributed under the terms and conditions of the Creative Commons Attribution (CC BY) license (http://creativecommons.org/licenses/by/4.0/). 